\title{
Assessment of A Lifesaver's Instantaneous Velocity in Mannequin Carry using Diferent Types of Fins
}

\author{
J.A. Abraldes ${ }^{1}$, R.J. Fernandes ${ }^{2, *}$, S. Soares ${ }^{2}$, A.B. Lima ${ }^{3}$ and J.P. Vilas-Boas ${ }^{2}$ \\ ${ }^{1}$ University of Murcia, Faculty of Sport Sciences, Murcia, Spain \\ ${ }^{2}$ University of Porto, Faculty of Sport, Cifi2d, Porto, Portugal \\ ${ }^{3}$ University Federal of Ceará, Fortaleza, Brazil
}

\begin{abstract}
The purpose of the study was to compare the instantaneous velocity produced by a lifesaver in a $25 \mathrm{~m}$ mannequin carry test, while performing barefoot and with four fin types. Comparisons between the first and second half parts of each test were also accomplished. Complementarily, the fatigue effect over the test distance was analyzed through the assessment of the slope of the velocity over time and of the fatigue index. One licensed male lifesaver performed $5 \times 25 \mathrm{~m}$ maximal swim test carrying a mannequin (barefoot and with flexible, short, stiff and fiber fin types). A cable speedometer was connected to the mannequin in order to measure instantaneous velocity. Results showed that swimming with barefoot does not allow high mannequin carries performances. Flexible fins were the ones that produce the lower velocity values in the $25 \mathrm{~m}$ mannequin carry effort. It was observed that fiber fins were the ones who allowed for higher mean velocity irrespectively of the effort part considered. Short and stiff fins use allowed for an increase of velocity during the first half effort part with a consequent reduction of fatigue effects. For the second half effort part, and for the total effort, short fins were the ones which induced lower velocity decay, followed by fiber fins. Short fins and fiber fins revealed the lower fatigue indexes. It was concluded that the selection of the best fin type is dependent of the fin length and could change with the effort distance.
\end{abstract}

Keywords: Biomechanics, fin swimming, mannequin carry, instantaneous velocity.

\section{INTRODUCTION}

Although fin swimming seem to be almost as old as swimming [1], the literature associated with the use of this auxiliary equipment that allows higher propulsion in aquatic environment is scarce. Being used in several aquatic activities, as well in sport context, fins are also used in sportive lifesaving, specifically in open water and swimming pool competitions. As sportive lifesaving is growing worldwide, there are specific regulations that establish the precise events in which fins are allowed to be used. These rules basically limit the maximal length and width of the fins, which allow the use of a great variety of models in lifesaving competitions. Besides some studies tried to assess the best fin model for use in competition events [2,3], no clear results were yet achieved.

The purpose of the present study was to compare the instantaneous velocity (v) produced by a lifesaver in a $25 \mathrm{~m}$ mannequin carry test, while performing barefoot and with four fin types. Comparisons between the first and second half parts of the test were also done. Complementarily, the fatigue effect over the test distance was analyzed through the assessment of the slope of the $\mathrm{v}(\mathrm{t})$ decline $\left(\mathrm{v}_{\text {decay }}\right)$ and of the fatigue index (FI).

*Address correspondence to this author at the Faculty of Sport, Porto University, Portugal; Tel: +351 225074763; E-mail: Ricfer@fade.up.pt

\section{METHODS}

One licensed male lifesaver with 15.4 years of age, 66.0 $\mathrm{kg}, 177.0 \mathrm{~cm}$ and a body mass index of 21.07 was studied. All the tests were performed on a short course indoor swimming pool with a mean depth of $2.00 \mathrm{~m}$. Water temperature was set at $27.5^{\circ} \mathrm{C}$.

The experimental protocol consisted on a $5 \times 25 \mathrm{~m}$ maximal swim test carrying a mannequin (Swedish model), with a recovery time of $30 \mathrm{~min}$, being the first repetition performed barefoot and the four others with the following fin types: (i) flexible fins (Gabbiano Francis), which were 45 $\mathrm{cm}$ in length and $20 \mathrm{~cm}$ in width; (ii) short fins (Deeply), measuring $42 \mathrm{~cm}$ in length and $26 \mathrm{~cm}$ in width; (iii) stiff fins (Cressi-sub) that were $59 \mathrm{~cm}$ in length and $20 \mathrm{~cm}$ in width and (iv) fiber fins (Special Films, model Sebak Saber 140 Hard $M$ ) with $65 \mathrm{~cm}$ long and $22 \mathrm{~cm}$ wide, being rectangular on its tail and rigid.

Each $25 \mathrm{~m}$ repetition began with in-water start, being the lifesaver in contact with the wall and holding the mannequin in a carrying position (lateral-dorsal). The total performance time in each $25 \mathrm{~m}$ trial was assessed manually through a digital stopwatch (Namaste). A cable speedometer [4] was connected to the mannequin in order to measure instantaneous $\mathrm{v}$ during total event duration. The speedometer uses an incremental sensor with 500 points resolution per revolution. 
During the data analysis, the first $2 \mathrm{~s}$ of the $\mathrm{v}$ curves of each swimmer were removed, which allowed minimizing the effect of the initial impulse resulting from the start and focused the analysis on the leg kicking actions only. Moreover, three $\mathrm{v}$ points were determined over $2 \mathrm{~s}$ periods on the curve, namely the mean $v$ correspondent to the initial 2-4 $\mathrm{s}$ of the total effort time $\left(\mathrm{v}_{\text {initial }}\right)$, the mean $\mathrm{v}$ correspondent to the $2 \mathrm{~s}$ of the middle of the total effort time $\left(\mathrm{v}_{\text {half }}\right)$ and the mean $\mathrm{v}$ correspondent to the last $2 \mathrm{~s}$ of total effort time $\left(\mathrm{v}_{\text {final }}\right)$. Total effort time was defined as the time duration between the first and the last $\mathrm{v}$ peak of the $\mathrm{v}(\mathrm{t})$ curve, after the initial impulse be removed. Additionally, the $\mathrm{v}$ correspondent to the first and second half parts of the test $\left(\mathrm{v}_{\text {mean1 }}\right.$ and $\mathrm{v}_{\text {mean2}}$, respectively), as well as to the total effort $\left(\mathrm{v}_{\text {meanT }}\right)$ were also carried out.

$\mathrm{v}_{\text {decay }}$ values, i.e. the mean slopes correspondent to the individual regression lines plotted between $v_{\text {initial }}$ and $v_{\text {half }}$, between $v_{\text {half }}$ and $v_{\text {final }}$ and between $v_{\text {initial }}$ and $v_{\text {final }}$ were also assessed. Likewise, the mean FI values correspondent to the first and second half of the event, and to the total effort time, were determined using the following equation:

$$
F I=(\bar{X} f \vec{v}-\bar{X} i \vec{v}) \cdot(\bar{X} f \vec{v} \cdot 100)
$$

where, $\bar{X} f \vec{v}$ is the mean $v$ of the second point and $\bar{X} i \vec{v}$ is the mean $v$ of the first point, of the two considered points used for its assessment.

\section{RESULTS}

In Fig. (1) it is possible to observe the instantaneous velocity curves averaged for each second during mannequin carry for each studied condition, i.e., barefoot and with the four different fin types.

Individual values correspondent to all studied parameters are reported in Table 1. It is possible to observe that mannequin carry mean $\mathrm{v}$ was lower in barefoot kicking comparatively with fins kicking irrespectively of the fin type, and irrespectively of the moment of the effort considered (initial, middle or final). Comparison between fin types showed that flexible fins were the poorest in velocity production at anyone of the three moments considered. Additionally, fiber fins allowed better performance than all the others.

When total effort time was divided in two half parts, it could be observed that flexible fins were again the ones that produce the lower $\mathrm{v}$ values in the $25 \mathrm{~m}$ mannequin carry effort. Complementarily, fiber fins were the ones who allowed for higher mean $\mathrm{v}$ irrespectively of the effort part considered.

The analysis of $\mathrm{V}_{\text {decay }}$ showed that short and stiff fins use allowed for an increase of $\mathrm{v}$ during the first half effort part with a consequent reduction of fatigue effects. For the second half effort part, and for the total effort, short fins were the ones $\mathrm{o}$ induced lower $\mathrm{v}$ decay, followed by fiber fins. The analyze of the $\mathrm{FI}_{\mathrm{T}}$ showed that short fins and fiber fins were the less tiring ones, which is in accordance with the global v results.

\section{DISCUSSION}

Results showed that swimming with barefoot is an insufficient condition for getting high mannequin carries performances, being the $\mathrm{v}$ displacement too low, with clear appearance of fatigue. Additionally, the selection of the best fin type seams to be dependent of the fin length. Indeed, when total $25 \mathrm{~m}$ carrying effort was considered, results showed that different types of fins seem to imply different propulsion effectiveness, being the stiff and mainly the fiber fins (the longer ones) the best ones to use in short carrying efforts. Flexible and short fins were less effective, only allowing higher $v$ than when swimming with barefoot. Nonetheless, it is important to refer that if carrying distances change it is possible that fin selection will have to change too. Short fins showed an excellent profile in what means $\mathrm{v}$ decay and FI. Those fins could eventually be a best option for higher carrying distances, namely by delaying the occurrence of a fatigue

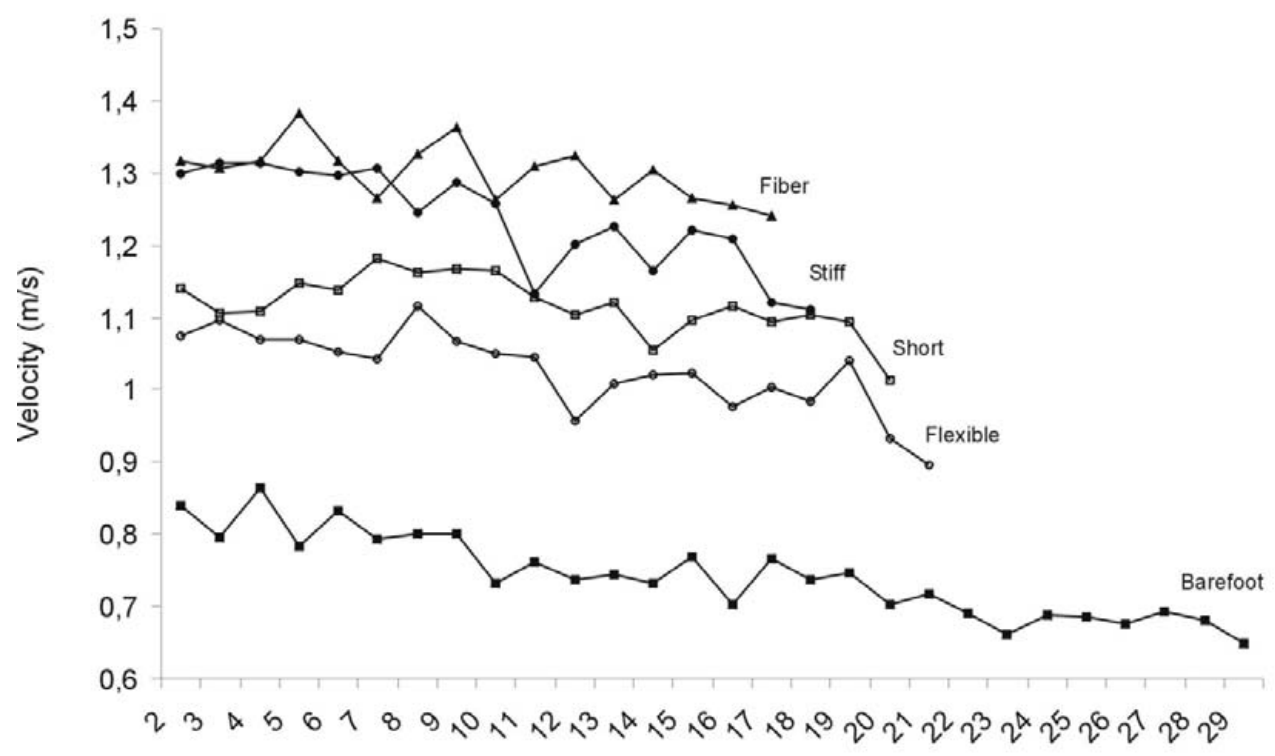

Time (s)

Fig. (1). Instantaneous velocity curves (averaged for each s of the test) obtained using the speedometer system for one lifesaver. 
Table 1. Individual Values Correspondent to Total Effort Time (t), v of Initial, Half and Final 2 s Periods, Mean v, v Decay and FI Per Half Part (1 and 2) and for the Total Effort (t), Obtained During Mannequin Carry with Barefoot, Flexible Fins, Short Fins, Stiff Fins and Fiber Fins

\begin{tabular}{|c|c|c|c|c|c|}
\hline & Barefoot & Flexible Fins & Short Fins & Stiff Fins & Fiber Fins \\
\hline $\mathrm{t}(\mathrm{s})$ & 28.18 & 19.64 & 18.32 & 16.22 & 15.54 \\
\hline $\mathrm{v}_{\text {half }}(\mathrm{m} / \mathrm{s})$ & 0.75 & 1.05 & 1.15 & 1.27 & 1.35 \\
\hline $\mathrm{v}_{\text {final }}(\mathrm{m} / \mathrm{s})$ & 0.64 & 0.94 & 1.09 & 1.16 & 1.27 \\
\hline $\mathrm{v}_{\text {meanT }}(\mathrm{m} / \mathrm{s})$ & 0.74 & 1.03 & 1.12 & 1.24 & 1.30 \\
\hline $\mathrm{v}_{\text {decay } 1}(\mathrm{~m} / \mathrm{s})$ & -0.07 & -0.04 & 0.02 & -0.04 & 0.03 \\
\hline $\mathrm{v}_{\text {decay } 2}(\mathrm{~m} / \mathrm{s})$ & -0.11 & -0.106 & -0.06 & -0.11 & -0.08 \\
\hline $\mathrm{v}_{\text {decayT }}(\mathrm{m} / \mathrm{s})$ & -0.18 & -0.14 & -0.04 & -0.15 & -0.05 \\
\hline $\mathrm{FI}_{\mathrm{T}}(\%)$ & 22.27 & 13.25 & 3.23 & 11.50 & 3.57 \\
\hline
\end{tabular}

threshold, who's existence as already been observed in free swimming [5].

\section{REFERENCES}

[1] Laurent B, Guillaume G, Charlie B. Finswimming research - past, present and future. In: Nomura T, Ungerechts B, Eds. Proceedings of the 1st International Scientific Conference of Aquatic Space Activities; 2008: Tsukuba: University of Tsukuba 2008; pp. 2-12. Abraldes JA. Evaluation of swim fins according to the time taken in swim tests and manikin tow tests. Cult Ciencia Dep 2006; 5(2): $67-2$.
[3]

Abraldes JA. The fins like fundamental element in the rescue and the sport. In: Abraldes JA, Rodríguez N, Eds. Abstracts of the International Lifesaving Congress 2007; pp. 41-2.

[4] Lima AB, Semblano P, Fernandes D, et al. A kinematical, imagiological and acoustical biofeedback system for the technical training in breaststroke swimming. Port J Sport Sci 2006; 6 (Suppl 1): 22.

[5] Soares S, Machado L, Lima A, et al. Velocimetric characterization of a $30 \mathrm{sec}$ maximal test in swimming: consequences for bioenergetical evaluation. Port J Sport Sci 2006; 6 (Suppl 2): 265-8.

(c) Abraldes et al.; Licensee Bentham Open.

This is an open access article licensed under the terms of the Creative Commons Attribution Non-Commercial License.

(http://creativecommons.org/licenses/by-nc/3.0/) which permits unrestricted, non-commercial use, distribution and reproduction in any medium, provided the work is properly cited. 